\title{
Surface Charges and Interfaces: Implications for Mineral Roles in Prebiotic Chemistry*
}

\author{
MILA PONTES-BUARQUE ${ }^{1}$, ANA C. TESSIS ${ }^{2}$, \\ JOSÉ A. P. BONAPACE ${ }^{3}$, MARISA B. M. MONTE ${ }^{4}$, \\ FERNANDO DE SOUZA-BARROS ${ }^{5}$ and ADALBERTO VIEYRA ${ }^{1}$ \\ ${ }^{1}$ Instituto de Biofísica Carlos Chagas Filho, Universidade Federal do Rio de Janeiro \\ 21941-590 Rio de Janeiro, RJ, Brazil \\ ${ }^{2}$ Instituto de Biologia, Universidade do Estado do Rio de Janeiro \\ ${ }^{3}$ Instituto de Química, Universidade Federal do Rio de Janeiro \\ ${ }^{4}$ Centro de Tecnologia Mineral, Ministério da Ciência e Tecnologia \\ ${ }^{5}$ Instituto de Física, Universidade Federal do Rio de Janeiro, Rio de Janeiro, Brazil \\ Manuscript received on March 30, 2000; accepted for publication on April 6, 2000; \\ contributed by ADALBERTO VIEYRA**
}

\begin{abstract}
There exists an extensive literature on the possible roles of minerals in the prebiotic stages of the chemical evolution of life (Bernal 1951, Cairns-Smith 1982, Wächtershäuser 1992, Vieyra et al. 1995, Tessis et al. 1999, see Lahav (1994) for a review). Among the original proposals, minerals have been considered in: (a) processes that would discriminate molecular chirality; (b) condensation reactions of biomolecular precursors; (c) prebiotic catalysis; (d) biochemical templates; and (e) autocatalytic metabolism. In this communication it is emphazised the complex properties of both surface reactions and interfaces between minerals and aqueous solutions simulating Archean scenarios. The properties of pyrite surface net charge and of its interface with a solution simulating primitive seawater are discussed and their implications to the autocatalytic model (Wächtershäuser 1988a 1992) are presented in order to demonstrate their relevance. The proposed roles of iron-sulfide minerals (mainly pyrite) as physical support for primitive bidimensional metabolism and chiral discriminator (Wächtershäuser 1988a, Huber \& Wächtershäuser 1998) are revised. It is shown that: (a) the net surface charge can be modulated by the pyrite-aqueous solution interface; (b) mononucleotides attachment to pyrite require a cationic bridge; and (c) direct absorption of acetate - a molecule proposed as carbon source in primitive aqueous environments - also modulates the interface properties and would have masked pyrite's bulk structure. These results indicate that physicochemical changes of mineral surfaces - caused by environments simulating Archean aqueous scenarios - should be taken into account in the proposals of mineral prebiotic roles.
\end{abstract}

Key words: prebiotic reactions, mineral interfaces, surface reactions.

\section{INTRODUCTION}

\footnotetext{
*Invited paper

** Member of the Academia Brasileira de Ciências

Correspondence to: Adalberto Vieyra

E-mail: avieyra@biof.ufrj.br
}

Wächtershäuser (1988a,b, 1992) proposes that the early stage of molecular evolution was an autotrophic process consisting of an autocatalytic metabolism confined to an essentially twodimensional monomolecular organic layer. These 
molecular structures would be anionically bonded to positively charged surfaces (e.g., pyrite). The energy for carbon fixation being provided by the redox process of converting ferrous ions and hydrogen sulfide into pyrite (Wächtershäuser 1988b 1994). The bound biomolecular precursors in turn would react with each other evolving through semicellular structures to primitive forms of life (Russell et al. 1994). This assumption has been recently reinforced (Vogel 1998).

In the Wächtershäuser model, the twodimensional system would be in an aqueous (seawater) environment having a passive role. The actual conditions prevailing when sulfur materials are in contact with salt solutions however are quite complex. The very reactive iron-sulfide immersed in a solution resembling a primitive ocean generates a continuously changing interface with ionic gradients (i.e. $\mathrm{Fe}^{2+}, \mathrm{Fe}^{3+}, \mathrm{H}^{+}$) and formation of different oxide layers (Evangelou \& Huang 1994, Xu \& Schoonen 1995, Schoonen et al. 1999). Little is known about the physicochemical properties of this complex and interactive system. In the standard representation of a mineral-solution interface such as that between pyrite and a solution that simulates Archean seawater (see the classical model of Brockris \& Reddy 1973), there are two main layers between the bulk material (pyrite in the present case) and the aqueous medium. The layer that contacts the aqueous medium - here called the outer layer - is characterized by diffuse ionic gradients (concentrations) which is much thicker than the layer that contacts the mineral, known as the Stern layer. The former is made of firmly attached ions and it is expected that an increase of both ionic or molecular species concentrations that can attach to the mineral surface results in the decrease of the Stern layer thickness, i.e., a clear indication of charge compensation mechanisms. It is the coupling of the bulk material and the Stern layer that determines the measured Zeta potential, i.e., the net charge of the mineral surface.

Recent results of electrophoretic measurements of Zeta potentials (Monte 1998, PontesBuarque et al. 2000) are briefly described in order to demonstrate the effects of aqueous enviroments on pyrite net surface charges. These measurements were carried out in order to investigate: a) charge modulation by different oxidation and $\mathrm{pH}$ conditions; and b) pyrite net charge in concentrated $\mathrm{Na}^{+}$. acetate and in artificial primitive sea water supplied with acetate.

\section{SURFACE NET CHARGE AND CATIONIC REQUIREMENT FOR MONOMER ATTACHMENT}

Determinations of oxidation and $\mathrm{pH}$ effects on the pyrite surface polarization were carried out in two independent sets of experiments; the first set was carried out by Monte (1998), and the second by Pontes-Buarque et al. (submitted). Monte (1998) observed that oxygen-free pyrite surfaces presents an isoelectric point (i.e.p.) at $p H 2$ with negative Zeta potentials for $p H>2$. This i.e.p. coincides with that for elementary sulfur (Healy \& Moignard 1997). The pyrite oxidation to elementary sulfur has been suggested as the cause for its hydrofobicity in acid medium. If there exists no conditions for polysulfides formation, the stable elementary sulfur would exihibit a molecular interaction character which is compatible with the proposed gain of hydrophobicity.

The elementary sulfur layer is virtually insoluble as such and theoretically unreactive with water, hence can not attract shells of oriented water molecule around it (hydration). Therefore sulfur layer appears to be expelled from aqueous medium and hence are designed hydrophobic (water hating), in constrast to soluble oxide/hidroxide layers and anions such as thiosulphate and sulphate, which are clearly hydrophilic (water loving).

The electrochemical reaction which produces hydrophobic surface species is:

$$
F e S_{2} \rightarrow F e^{2+}+2 S^{0}+2 e^{-}
$$

The mechanism of sulfur oxidation is less clearly established than the iron oxidation. Hamilton \& Woods (1981) assumed that sulfur exists either as elemental sulfur or as sulfate. Based on this assumption, they demonstrated that the amount of 
sulfur layer remains constant in alakaline solutions, whereas the amount of the oxidized sulfur species (assumed $\mathrm{SO}_{4}^{2-}$ ) increases as oxidation of pyrite proceeds.

Monte's results (1998) show that the negative

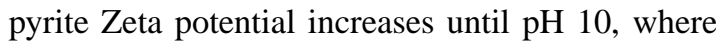
it is expected that the dominant surface species is [ $\left.\mathrm{Fe}(\mathrm{OH})_{3}\right]$ (Acar \& Somasundaran 1992). Hydrogen peroxide was also used to characterize the oxidizing effect upon the pyrite surface polarizarion. Hydrogen peroxide by itself rendered pyrite surfaces very hydrophilic (Monte et al. 1997). Although $\mathrm{pH}$ dependent, hydroxo-oxo species with ionic character are expected to be very hydrophilic. The electrophoretic measurements showed that the pyrite surface is completely oxidized by hydrogen peroxide, with an isoelectric point at $\mathrm{pH} 5.5$ (see also Fornasiero et al. 1992). These results suggest that oxygen could be responsible for charge reversal of pyrite net charges for $p H<5.5$, a region in which hydroxide-complexes $\left(\left[\mathrm{Fe}(\mathrm{OH})_{2}\right]^{+}\right.$and $[\mathrm{Fe}(\mathrm{OH})]^{2+}$ ) should be present on the pyrite surfaces (Fornasiero et al. 1992, Kydros et al. 1993). Thus hydrogen peroxide would create a pyrite interface with i.e.p. 5.5, i.e., close to that observed for iron oxides (Fuerstenau \& Raghavan 1976, Yoon et al. 1979). Infrared data obtained in Monte's experiments also confirmed the reported high pyrite sensitivity to oxygen action (Evangelou \& Huang 1994).

The hydrophilicity of pyrite surface in strongly alkaline solutions was related to hydrolysis of ferrous ions to ferrous hydroxide and then oxidation of ferrous hydroxide to ferric hydroxide as proposed by Chander \& Briceno (1987):

$$
\begin{gathered}
\mathrm{Fe}^{2+}+2 \mathrm{H}_{2} \mathrm{O} \leftrightarrow \mathrm{Fe}(\mathrm{OH})_{2}+2 \mathrm{H}^{+} \\
\mathrm{Fe}(\mathrm{OH})_{2}+\mathrm{OH}^{-} \leftrightarrow \mathrm{Fe}(\mathrm{OH})_{3}+e^{-}
\end{gathered}
$$

It should be noted that prebiotic hydrophobichydrophilic transition mechanisms should have eventually been evolved into energy-transducers of biological systems. Conspicuous catalitic cycles of modern energy-transducer enzymes exhibit these transitions at their active centers (de Meis 1989). Subtle changes in hydrophilic-hydrophobic character due to fluctuations of local oxygen concentrations (Kasting 1997) would simulate the modulation behavior compatible with the known catalytic cycles in modern energy-transducer enzymes (Tessis et al. 1999, Pontes-Buarque et al. 2000).

For the second set of experiments been reported (Pontes-Buarque et al. 2000) hydrofluoric acid (HF) removal of superficial oxides was carried out using a procedure (Tessis et al. 1999) close to that described by Evangelou \& Huang (1994) and Xu \& Schoonen (1995). In this set of results, untreated pyrite samples, i.e., with no previous HF treatment, presented a positive Zeta potential with a maximal at $\mathrm{pH} 5.0$ indicating a positive net charge for the pyrite particles. As $\mathrm{pH}$ increases, a polarity change is observed at $\mathrm{pH}$ 6.8 , beyond which the particles exhibit a negative net charge. In contrast, HF-treated particles have negative charges at $\mathrm{pH}$ below 6.0 when suspended either in concentrated acetate or in a mixture of acetate with artificial primitive sea water. It is also observed that the i.e.p. value obtained with untreated particles is close to that of iron hydroxide species $\left(\mathrm{Fe}(\mathrm{OH})_{2}\right.$ and $\mathrm{Fe}(\mathrm{OH})_{3}$ ) (Yoon et al. 1979, Fornasiero et al. 1992), confirming that oxygen is responsible for the observed positive polarity reversal. It was concluded that the HF surface treatment removes ferric oxide from the pyrite samples, revealing the negative polarity that should be expected for this matrix when in the presence of $\mathrm{O}_{2}$-depleted media such as those of primitive Earth scenarios. In this situation divalent cations are imperative requirements for the 5'-AMP adsorption on HF-treated pyrite at $\mathrm{pH} 5.0$ (Pontes-Buarque et al. 2000). The data also show that both $\mathrm{Ca}^{2+}$ and $\mathrm{Mg}^{2+}$ - the prevalent divalent cations of primitive oceans (Snyder \& Fox 1975) are equally efficient. Previous studies have shown that the presence of divalent cations, such as $C u^{2+}$ or $\mathrm{Zn}^{2+}$, increases the adsorption of nucleotides on the surface of montmorillonite clay (Lawless et al. 1985, Banin et al. 1985). Divalent cations can also modulate the adsorption of 5'-AMP in phosphate minerals (Tessis \& Vieyra 1996) and are absolute re- 
quirements for the adsorption of 5'-ATP onto pyrite (Tessis et al. 1999). Thus, the need of a bridge of divalent cations for nucleotide attachment onto the surface of pyrite appears to be a general feature to be considered in any model of pyrite-substrate interactions (Wächtershäuser 1988b).

\section{STERN-LAYER MODULATION EFFECTS DUE TO ACETATE}

The incorporation by the Stern layer of precursor molecules present in primitive aqueous scenarios (Ferris 1997) could have also modulated the adsorptive surface of minerals such as pyrite. PontesBuarque et al. (2000) also show the effects due to the direct acetate incorporation to pyrite's Stern layer. The interface studied was that between an oxide-depleted pyrite sediment and a concentrated solution of $\mathrm{Na}^{+}$-acetate at $\mathrm{pH}$ 5.0. This choice is based on the fact that $\mathrm{Na}^{+}$is the most abundant cation present in marine aqueous environments and that it was also the prevalent monovalent cation in primeval sea (Snyder \& Fox 1975, Seyfried et al. 1991, Simoneit 1992). Their most relevant features are: a) acetic acid is formed in potentially prebiotic conditions in the presence of iron-sulfides precipitates (Huber \& Wächtershäuser 1997); b) acetate attaches strongly onto pyrite (Tessis et al. 1999); and c) acetate enhances 5'-ATP adsorption onto this crystalline matrix (Tessis et al. 1999). It is therefore interesting that an universal precursor of carbon compounds in living systems is able to promote radical changes on pyrite adsorptive and catalytic properties.

\section{WAS A CHIRALITY-TEMPLATE ROLE ATTAINABLE TO MINERALS IN PRIMITIVE EARTH?}

The preferential adsorption of one enantiomer of a racemate onto one of the morphologically right- or left-handed crystal forms of quartz was first proposed as potentially responsible for the origin of chiral molecules in Nature over 50 years ago (see Bonner (1995) for a review). However the equal abundance on Earth of both righ- and left-handed quartz and the scrupulously anhydrous conditions required to enable the occurrence of measurable asymmetric adsorption on quartz render the mechanism totally implausible in any realistic prebiotic environment. There is no experimental evidence whatsoever to date supporting any stereoselective effects on prochiral or racemic substrates attributable to clay minerals (Bonner 1995). Pyrite has been hypothesized by Wächtershäser as a candidate as a chiral template (Wächtershäuser 1988b). In a pyritepulled chemo-autotrophic surface metabolism, the organic constituents are seen as being produced in intimate contact with the mineral which is assumed with a chiral configuration (Bayliss 1989). One could thus speculate that in early stages of chemical evolution, a lower rate of detachment of D- than Lnucleotides from the crystal surface with one enantiopolar direction could have promoted accumulation of nucleotides which spiral to the right. The results of Tessis et al. (1999) and Pontes-Buarque et al. (2000) show that the assignment of a chiralitytemplate role to pyrite might not be attainable. Even though there is the possibility of positive regions in a surface with a net negative charge, it must be emphasized that nucleotide attachment does not take place in the absence of divalent cations (Tessis et al. 1999). The results also indicate that the Stern layer modulates the polarity of the pyrite+interface system (Pontes-Buarque et al. 2000). In particular, acetate coating would also modulate the access of incoming ions from the diffuse layer into the Stern layer. Thus surface charge modulation, the unique acetate adsorptive behavior, together with the requirement for divalent cations in the attachment of organic key molecules, challenge this particular chiral-discriminator character of pyrite-substrate interactions in extant metabolism.

\section{ACKNOWLEDGEMENTS}

This paper is dedicated to the memory of Prof. Carlos Chagas Filho.

The authors thank CNPq, FAPERJ and FUJB/ UFRJ for the continuous support for their work. 


\section{REFERENCES}

Acar S \& Somasundaran P. 1992. Effect of dissolved mineral species on the electrokinetic behavior of sulfides. Minerals Engeneering 5: 27-40.

Banin A, Lawless JG, Mazzurco J, Church FM, Margulies L \& Orenberg JB. 1985. pH profile of the adsorption of nucleotides onto montmorillonite. II. Adsorption and desorption of 5'-AMP in ironcalcium montmorillonite systems. Orig Life Evol Biosph 15: 89-101.

BAYLISS P. 1989. Crystal chemistry and crystallography of some minerals within the pyrite group. Amer Mineralogist 74: 1168-1176.

Bernal JD. 1951. The physical basis of life. Routledge and Kegan Paul, London.

Bonner W. 1995. Chirality and life. Orig. Life Evol. Biosph. 25: 175-190.

BROCKRIS JOM \& REDDY AKN. 1973. Modern electrochemistry. Plenum Press, New York.

CAIRns-Smith AG. 1982. Genetic takeover and the mineral origins of life. Cambridge University Press, London.

Chander S \& Briceno A. 1987. Kinetics of pyrite oxidation. Miner Metall Process 10: 113-118.

DE MeIs L. 1989. Role of water in the energy of hydrolysis of phosphate compounds - energy transduction in biological membranes. Biochim Biophys Acta 728: 333-349.

Evangelou VP \& HuANG X. 1994. Infrared spectroscopic evidence of an iron(II)-carbonate complex on the surface of pyrite. Spectrochimica Acta 50: 13331340.

FERRIS JP. 1997. Chemical markers of prebiotic chemistry in hydrothermal systems. Comentarii 4: 165-195.

Fornasiero D, Eijt V \& Ralston J. 1992. An electrokinetic study of pyrite oxidation. Colloids \& Surfaces 62: 63-73.

Fuerstenau DW \& Raghavan S. 1976. Some aspects of the thermodynamics of flotation. In: FUERSTENAU MC (Ed); Flotation, AM Gaudin Memorial No. 3. SME/AIME, New York.
Hamilton IC \& Woods R. 1981. An investigation of surface oxidation of pyrite and pyrrhotite by linear potential sweep voltammetry. J Electroanal Chem 118: $327-343$

Healy TW \& Moignard MS. 1997. A review of electrokinetic studies of metal sulphides. In: FuERSTENAU MC (Ed); Flotation, AM Gaudin Memorial No. 9. SME/AIME, New York.

Huber C \& Wächtershäuser G. 1997. Activated acetic acid by carbon fixation on (Fe,Ni)S under primordial conditions. Science 276: 245-247.

Huber C \& Wächtershäuser G. 1998. Peptides by activation of amino acids with $\mathrm{CO}$ on $(\mathrm{Ni}, \mathrm{Fe})$ surfaces: Implications for the origin of life. Science 281: 670672 .

KASTING JF. 1997. Environmental constraints on the origin of life. Comentarii 4: 133-145.

Kydros K, Matis KA \& Stalidis G. 1993. Cationic flotation of pyrites. J Coll Interf Sci 155: 409-414.

Lahav N. 1994. Minerals and the origin of life: Hypotheses and experiments in heterogeneous chemistry. Het Chem Rev 1: 159-179.

Lawless JG, Banin A, Church FM, Mazzurco J, Huff R, Kao J, Cook A, Lowe T, Orenberg JB \& EDELSON E. 1985. $\mathrm{pH}$ profile of the adsorption of nucleotides onto montmorillonite. Orig Life Evol Biosph 15: 77-88.

MonTe MB. 1998. Gold and pyrite surface properties: their separation by flotation. $\mathrm{PhD}$ thesis (in Portuguese), COPPE-UFRJ, Rio de Janeiro.

Monte MB, Lins FF \& Oliveira JF. 1997. Selective flotation of gold from pyrite under oxidizing conditions. Int J Miner Process 51: 255-267.

Russell MJ, Daniel RM, Hall AJ \& Sherringham JAA. 1994. A hydrothermally precipitated catalytic iron sulphide membrane as a first step toward life. $J$ Mol Evol 39: 231-143.

Schoonen MAA, Xu Y \& Bebie J. 1999. Energetics and kinetics of the prebiotic synthesis of simple organic acids amino acids with the $\mathrm{FeS}-\mathrm{H}_{2} \mathrm{~S} / \mathrm{FeS}_{2}$ redox couple as reductant. Orig Life Evol Biosph 29: 5-32. 
Seyfried WE Jr, Ding K \& Berndt ME. 1991. Phase equilibria constraints on the chemistry of hot spring fluids at mid-ocean ridges. Geochim Cosmochim Acta 55: 3559-3580.

SimONEIT BRT. 1992. Aqueous organic geochemistry at high temperature/high pressure. Orig Life Evol Biosph 22: 43-65.

SNYDER WD \& Fox SW. 1975. A model for the origin of stable protocells in a primitive alkaline ocean. BioSystems 7: 222-229.

Tessis AC \& Vieyra A. 1996. Divalent cations modify adsorption of 5'-AMP onto precipitated calcium phosphate: A model for cation modulation of adsorptive processes in primitive aqueous environments. $J$ Mol Evol 43: 425-430.

Tessis AC, Penteado-Fava A, Pontes-Buarque M, AMORIM HS DE, Bonapace JAP, Souza-Barros F DE \& VIEYRA A. 1999. Pyrite suspended in artificial sea water catalyzes hydrolysis of adsorbed ATP: Enhancing effect of acetate. Orig Life Evol Biosph 29: 361-374.

Vieyra A, Gueiros-Filho F, Meyer-Fernandes JR, Costa-Sarmento G \& Souza-Barros F De. 1995. Reactions involving carbamyl phosphate in the presence of precipitated calcium phosphate with formation of pyrophosphate: A model for primitive energyconservation pathways. Orig Life Evol Biosph 25: 335-350.
Vogel G. 1998. A sulfurus start for protein synthesis? Science 281: 627-629.

WÄCHTERSHÄUSER G. 1988a. Pyrite formation, the first energy source for life: a hypothesis. System Appl Microbiol 10: 207-210.

WÄCHTERSHÄUSER G. 1988b. Before enzymes and templates: theory of surface metabolism. Microbiol Rev 52: $452-484$

WÄCHTERSHÄUSER G. 1992. Groundworks for an evolutionary biochemistry: the iron-sulfur world. Prog Biophys Molec Biol 58: 85-201.

WächtershäUSER G. 1994. Life in a ligand sphere. Proc Natl Acad Sci USA 91: 4283-4287.

XU Y \& Schoonen MAA. 1995. The stability of thiosulfate in the presence of pyrite in low-temperature aqueous solutions. Geochim Cosmochim Acta 59: 4605-4622.

Yoon RH, Salman T \& DONNAY G. 1979. Predicting points of zero charge and hydroxides. J Colloid Interface Sci 70: 483-493. 